\title{
MicroRNA-769-5p Inhibits Pancreatic Ductal Adenocarcinoma Progression by Directly Targeting and Downregulating ETS Proto-Oncogene I [Retraction]
}

Cheng K, Feng L, Yu S, Yu C, Chi N. Onco Targets Ther. 2019;12:11737-11750.

The Editor and Publisher of OncoTargets and Therapy wish to retract the published article. Concerns were raised over alleged image duplication in Figures $2 \mathrm{C}, 5 \mathrm{C}$ and $6 \mathrm{C}$ with similar images from unrelated articles, specifically:

- Figure 2C, panel Panc-1 miR-NC appears to have been duplicated with a similar image in Figure 6D from Lv et al, 2019 (https://doi.org/10.2147/CMAR. S199818).

- Figure 5C, panel Panc-1 si-ETS1 appears to have been duplicated with a similar image in Figure 4B from Yin et al, 2020 (https://doi.org/10.2147/OTT. S240022).

- Figure 6C, panel Sw1990 miR-NC appears to have need duplicated with a similar image in Figure 5E from Yan et al, 2019 (https://doi.org/10.3892/ijmm. 2019.4245).

- Figure 6C, panel Sw1990 miR-769 mimics + pcDNA3.1 appears to have been duplicated with a similar image in Figure 4C from Lyu et al, 2019 (https://doi.org/10.3892/or.2019.7061).

- Figure 6C, panel Sw1990 miR-769 mimics + pcDNA3.1-ETS appears to have been duplicated with a similar image in Figure 4B from Yin et al, 2020 (https://doi.org/10.2147/OTT.S240022).

- Figure 6C, panel Panc-1 miR-769 mimics + pcDNA3.1 appears to have been duplicated with a similar image in Figure 2D from Yang et al, 2019 (https://doi.org/10.2147/OTT.S204715).

The authors did not respond to our queries and the Editor determined the findings of the study were no longer valid and advised for the article to be retracted.

Our decision-making was informed by our policy on publishing ethics and integrity and the COPE guidelines on retraction.

The retracted article will remain online to maintain the scholarly record, but it will be digitally watermarked on each page as "Retracted".

\section{Publish your work in this journal}

OncoTargets and Therapy is an international, peer-reviewed, open access journal focusing on the pathological basis of all cancers, potential targets for therapy and treatment protocols employed to improve the management of cancer patients. The journal also focuses on the impact of management programs and new therapeutic agents and protocols on patient perspectives such as quality of life, adherence and satisfaction. The manuscript management system is completely online and includes a very quick and fair peer-review system, which is all easy to use. Visit http://www.dovepress.com/ testimonials.php to read real quotes from published authors. 